\title{
KONTRIBUSI KOMITMEN BERAGAMA ORANG TUA TERHADAP PENGASUHAN HOLISTIK
}

\author{
Sri W Rahmawati \\ Fakultas Psikologi Universitas Tama Jagakarsa. \\ J1. Letjen T.B Simatupang No.152, Tanjung Barat, Jakarta Selatan, 12530 \\ swrahma@yahoo.com
}

\begin{abstract}
Religion becomes a fundamental factor of a person that influence individual's daily life, including his or her role as a parent. This study aims to explore the contribution of parents' religious commitment to the application of the holistic parenting based on Islamic concept. The holistic parenting includes five dimensions: qudwah hasanah (integrated role model), al addah (habituation), al mau'idzah (effective advice), al mulahadzah (fairness in care and control), and uqubah wa ujaroh (proportional consequences). 68 parents from an Islamic elementary school were involved in this study as respondents who were chosen using purposive sampling technique. The study used a quantitave method with Religious Commitment Inventory and Holistic Parenting Scale to measure the data. Results indicate significant positive correlations between religious commitment and its dimensions to holistic parenting. We conclude that parents' religious commitment influence holistic parenting that further open possibility for values transmission to their children.
\end{abstract}

Keywords: holistic parenting, islamic parenting, religious commitment

\begin{abstract}
Abstrak
Agama menjadi faktor fundamental yang mempengaruhi cara individu menjalani kehidupan sehari-hari, termasuk perannya sebagai orang tua. Penelitian ini bertujuan untuk mengeksplorasi kontribusi komitmen beragama orang tua terhadap penerapan pengasuhan holistik yang berlandaskan pada ajaran Islam. Konsep pengasuhan holistik meliputi: qudwah hasanah (contoh terpadu), al addah (pembiasaan), al mauidzah (nasehat efektif), al mulahadzah (keseimbangan dalam perhatian dan pemantauan), serta uqubah wa ujaroh (konsekuensi yang proporsional). 68 orang tua dari sebuah sekolah dasar Islam (SD) menjadi responden dalam penelitian ini yang dipilih dengan menggunakan teknik sampling purposif. Penelitian ini menggunakan pendekatan kuantitatif dengan skala komitmen beragama (Religious Commitment Inventory) dan skala pengasuhan holistik sebagai alat ukur. Hasil penelitian menunjukkan terdapat hubungan positif yang signifikan antara komitmen beragama dan dimensi-dimensinya terhadap teknik pengasuhan holistik. Pilihan orang tua untuk menerapkan pengasuhan holistik yang mentransmisikan nilai-nilai agama yang dimiliki kepada anak-anak mereka dipengaruhi komitmen beragamanya.
\end{abstract}

Kata kunci: komitmen beragama, pengasuhan holistik, pengasuhan Islami 


\section{Pendahuluan}

Penelitian mengenai parenting (pengasuhan anak oleh orang tua) banyak menitikberatkan pada gaya parenting yang dikenal luas oleh para ahli psikologi perkembangan. Gaya parenting terbagi ke dalam dua dimensi besar: yang pertama terkait dengan kontrol, tuntutan, proteksi, supervisi, ataupun regulasi tingkah laku (Lane, 2015; Hughoghi \& Long, 2004) dan dimensi yang kedua berkaitan dengan kehangatan, keterlibatan, perhatian dan penerimaan (Mounts, 2002; Gammon, 2016). Berdasarkan dua dimensi utama tersebut, maka berkembanglah empat gaya pengasuhan yang merupakan kombinasi antar dimensi, yaitu gaya parenting yang tinggi pada kedua dimensi; sama-sama rendah pada kedua dimensi, dan dua kombinasi berikutnya adalah salah satu dimensi tinggi, sementara yang lainnya rendah; serta sebaliknya. Secara umum prinsip-prinsip dasar pengasuhan mengacu pada gaya pengasuhan berdasarkan dua dimensi utama tersebut (Spraitz, 2011).

Pengasuhan anak dengan cara yang tepat penting dilakukan oleh orang tua, sebagai upaya untuk memastikan tersampaikannya nilai-nilai yang dianut oleh orang tua, yang terwujud dalam bentuk sikap, kebiasaan maupun perilaku sehari-hari kepada anak (Ulwan, 2014). Khazanah Islam memiliki metode pengasuhan yang bersifat komprehensif dan berlandaskan pada dalil-dalil Al Qur'an maupun Al Hadits. Pengasuhan yang berdasar Al Qur'an dan Al Hadits disebut dengan pengasuhan holistik yang merupakan pendekatan dalam pola mendidik anak yang menjadi terobosan baru di bidang psikologi perkembangan (Ulwan, 2014). Pengasuhan ini menjadi praktik yang berkembang dalam masyarakat muslim Indonesia, yang dikenal sebagai masyarakat religius dengan tradisi, budaya maupun kebiasaan yang terpelihara bertahun-tahun (Rahmawati, 2016). Diskursus mengenai pengasuhan Islami dapat ditemui pada beberapa konsep yang disosialisasikan dalam bentuk kelas-kelas parenting seperti positive parenting (Adhim, 2015), parenting nabawiyah dan prophetic parenting (Hafizh, 2012). Namun demikian, penelitian yang berfokus pada pola pengasuhan anak dengan dasar religius ini belum banyak ditemukan. Di sisi lain, menguatnya fenomena keagamaan berimbas pula pada tingginya minat orang tua mendalami agama, termasuk dalam menerapkan teknik pengasuhan anak yang berlandaskan Al Qur'an dan Al Hadits (Adhim, 2015; Hafizh, 2012).

Dalam khasanah Islam, berbagai ulama mengkaji konsep Islamic parenting, yang dikenal dengan istilah tarbiyatul aulad. Dari sekian konsep tarbiyaul aulad yang ada, maka gagasan Ulwan (2014) dianggap oleh mayoritas pendidik sebagai gagasan yang komprehensif. Konsep Islamic parenting ini dinamakan sebagai holistic parenting (pengasuhan holistik) karena memiliki sifat yang komprehensif yang memadukan praktik pengasuhan praktis dengan muatan nilai-nilai religius (dalam hal ini Islam) (Rahmawati, 2017a). Konsep ini bukan hanya menempatkan pengasuhan sebagai upaya membangun iklim psikologis antara orangtua dan anak saja, namun juga memadukannya dengan penerapan prinsip pengasuhan praktis secara simultan (Rahmawati, 2017a).

Pengasuhan holistik memiliki lima dimensi, yang merupakan teknik-teknik dalam pengasuhan anak yang tercermin pada prinisip-prinsip pengasuhan maupun dimensi-dimensinya. Dimensi-dimensi pengasuhan holistik meliputi: qudwah hasanah (integrated role model/contoh terpadu), al addah (habituation/pembiasaan), al mauidzah (effective advice/nasehat efektif), al mulahadzah (fairness in care and control/keseimbangan dalam perhatian dan pemantauan), serta uqubah wa ujaroh 
(proportional consequences/konsekuensi yang proporsional)(Rahmawati, 2017a; Ulwan, 2014).

Nilai-nilai Islam pada setiap dimensi tercermin pada teknik-teknik pengasuhan yang digunakan, yang berlandaskan pada Al Qur'an maupun Al Hadits. Sebagai contoh dimensi qudwah hasanah, dimensi ini menekankan pada pengasuhan melalui role model. Role model perlu dilakukan seorang pendidik. Seorang pendidik hendaknya menjadi contoh bagi anak dalam tingkah laku yang positif. Hal ini didasarkan pada ayat Al Qur'an surat Al Ahzab ayat 21, yang berarti "Sesungguhnya telah ada pada (diri) Rasullullah itu suri tauladan yang baik bagimu (yaitu) bagi orang yang mengharap rahmat Allah dan (kedatangan) hari akhirat dan dia banyak menyebut nama Allah".

Contoh lain adalah dimensi al addah, yang merupakan teknik pembiasaan adabadab Islam pada anak. Hal ini sesuai hadits Rasulullah SAW yang diriwayatkan oleh Al Hakim dan Abu Dawud, dari Abdullah bin Amr bin Al Ash, beliau SAW bersabda "perintahkanlah anak-anak kalian sholat saat mereka berusia 7 tahun, dan pukullah mereka ketika meninggalkan sholat pada saat berusia 10 tahun, serta pisahkanlah tempat tidur mereka" (Ulwan, 2014) . Pada hadits tersebut, teknik pembiasaan (al 'addah) dalam mendidik anak diterapkan secara konsisten baik dari sisi waktu pelaksanaan, maupun dari sisi pembiasaan perintah oleh pendidik. Hal tersebut dimaksudkan agar perilaku positif (seperti sholat, dan perilaku positif lainnya) tertanam secara kuat pada diri anak.

Dimensi al mauidzah, merupakan teknik pengasuhan yang menekankan pada nasehat yang efektif. Hal ini didasarkan pada ayat dalam Al Quran Surat An Nahl yang berbunyi: "Serulah (manusia) kepada jalan Rabb-mu dengan hikmah dan pelajaran yang baik dan bantahlah mereka dengan cara yang lebih baik." (QS An Nahl:125). Dalam surat An Nahl: 125 ini, mufassir Ibnu Katsir menjelaskan bahwa Allah SWT memerintahkan Rasulullah SAW mengajak manusia dengan hikmah, yakni dengan berbagai larangan dan perintah yang terdapat dalam Al Qur'an. Allah SWT juga memerintahkan Rasulullah SAW untuk mengedepankan dialog secara lembut, halus dan bahasa yang sopan. Hal yang serupa juga diperintahkan Allah kepada Nabi Musa A.S dan Harun A.S saat diutus menghadap Fir'aun.

Selanjutnya dimensi al mulahadzah merupakan teknik pengasuhan yang menekankan pada perhatian dan kontrol yang diberikan secara berimbang. Perhatian artinya adalah membangun suasana psikologi sehingga anak dan orang tua memiliki kedekatan emosi. Sementara kontrol berarti pengawasan terhadap tingkah laku anak. Kontrol merupakan cara agar anak tetap menunjukkan tingkah laku yang sesuai aturan. Dalil-dalil yang tercantum dalam Al Qur'an maupun Al Hadits, menekankan pentingnya memberikan perhatian dan pemantuan pada berbagai area perkembangan anak, baik area perkembangan mental, jasmani, sosial maupun ruhani.

Pada perkembangan mental, misalnya, terdapat hadits yang memerintakan untuk memperlakukan anak secara adil dan tidak diskriminatif. "Seorang sahabat datang kepada Rasulullah dengan membawa anaknya. Sahabat itu berkata: "aku memberi hadiah anakku ini dengan seorang budak milikku". Kemudian Rasulullah berkata: “apakah setiap anak engkau beri hadiah sama sepertinya?" Ia menjawab: "tidak". Lalu berliau berkata: " kalau begitu ambillah kembali." (Hadits Riwayat Bukhari dan Muslim dalam Ulwan, 2014). Sementara perintah untuk memberikan perhatian dan pemantauan pada area perkembangan fisik anak tercermin pada hadits: "Ajarkanlah anakmu tiga hal: berenang, berkuda dan memanah" (Hadits Riwayat Ath Thabrani dalam Ulwan, 2014). 
Teknik pengasuhan yang terakhir yaitu uqubah wa ujaroh (proportional consequences//konsekuensi yang proporsional). Pemberian konsekuensi perlu diterapkan kepada anak ketika melakukan pelanggaran, agar menjadi efek jera. Konsekuensi dilakukan dengan menyepakati aturan main terlebih dahulu dengan anak. Namun Islam menggariskan agar pemberikan konsekuensi mengikuti prinsip-prinsip tertentu, seperti pendidik melakukannya dengan sikap lemah lembut terhadap anak, pendidik memperhatikan karakter anak, pendidik memberi hukuman secara bertahap dari ringan hingga hukuman yang keras.

Kajian mengenai pengasuhan anak penting dilakukan karena tuntutan perkembangan di masa kini menyajikan tantangan bagi orang tua untuk menemukan pola asuh yang tepat sejalan dengan proses pendidikan yang ingin ditanamkan dalam keluarga (Mount, 2002). Pengasuhan holistik merupakan alternatif pilihan pengasuhan orang tua yang dianggap sesuai dengan tradisi mayoritas masyarakat Indonesia yang berpegang teguh ajaran Islam (Rahmawati, 2016).

Praktik pengasuhan holistik sebagai alternatif pilihan orang tua saat melakukan pengasuhan pada anak-anaknya, diduga tidak terlepas dari komitmen beragama yang dimiliki. Worthington, dkk. (2003) mendefinisikan komitmen beragama sebagai tingkatan kesetiaan seorang mengikuti nilai, kepercayaan, dan ritual agamanya serta menerapkannya dalam kehidupan sehari-hari. Seseorang dengan komitmen beragamaan yang tinggi akan memandang dunianya dengan skema religius dan akan mengintegrasikan agamanya pada seluruh aspek kehidupannya. Terdapat delapan indikator yang dapat digunakan untuk mengukur komitmen beragama, yaitu seberapa sering mereka datang ke tempat ibadah, keikutsertaan dalam kegiatan-kegiatan di tempat ibadah, kebersetujuan terhadap ajaran-ajaran agama atau terhadap kebijakan pemimpin agama, seberapa sering membaca kitab suci, self-report mengenai intensitas diri mereka dalam mengidentifikasikan diri terhadap agamanya, kegiatan ritual yang dilakukan, bagaimana kepercayaan dalam agama digunakan dalam pengambilan keputusan sehari-hari, dan keanggotaan formal dalam institusi agama (Worthington et al., 2003). Indikator-indikator tersebut digolongkan ke dalam dua hal pokok komitmen beragama intrapersonal dan komitmen beragama interpersonal. Komitmen beragama intrapersonal berkaitan dengan penghayatan di dalam diri individu untuk merasakan kehadiran Allah SWT serta mengagumi ciptaan Allah SWT dengan indikator kebersetujuan terhadap ajaran-ajaran agama atau kebijakan pemimpin agama, kepercayaan dalam agama digunakan dalam pengambilan keputusan sehari-hari dan self-report mengenai intensitas diri mereka dalam mengidentifikasikan diri terhadap agamanya. Sementara komitmen beragama interpersonal berkaitan dengan penghayatan individu dalam relasinya dengan orang lain, maupun dengan organisasi keagamaan. Komitmen beragama interpersonal berupa seberapa sering datang ke tempat ibadah, keikutsertaan dalam kegiatan di tempat ibadah, seberapa sering membaca kitab suci, kegiatan ritual yang dilakukan, dan keanggotaan formal dalam institusi agama.

Pada kehidupan sehari-hari, komitmen beragama ditunjukkan pada sikap dan tingkah laku individu yang diambil saat menjalankan peran tertentu (Jones, 2012) termasuk saat menjalankan peran sebagai orang tua dalam pengasuhan pada anak (Lane, 2015). Orang tua menerapkan pola pengasuhan tertentu dalam mendidik, mengembangkan, dan mengajarkan nilai-nilai tertentu dalam keluaga. Bagi keluargakeluarga muslim yang memiliki visi dan misi berlandaskan Al Qur'an dan Al Hadits, komitmen keberagamaan ini akan mewarnai tata cara pengasuhan anak (Ulwan, 2014; Rahmawati, 2017a). Sebagai contoh orang tua yang sering terlibat dalam kegiatan 
keagamaan akan diikuti oleh anak. Dalam hal ini peran orang tua sebagai panutan (role model) akan mempengaruhi perkembangan, sikap dan nilai-nilai yang dimiliki anak (Hughoghi \& Long, 2004; Rahmawati, 2016). Anak yang tumbuh di lingkungan religius akan memiliki sikap yang positif terhadap aturan-aturan agama (Lane, 2015). Penelitian ini berupaya mengkaji peran komitmen beragama orang tua terhadap praktik pengasuhan holistik dalam proses pengasuhan anak.

\section{Metode Penelitian}

Penelitian ini menggunakan pendekatan kuantitatif. Responden yang menjadi subyek penelitian sebanyak 68 orang tua beragama Islam yang menyekolahkan anaknya pada SD Islam X. Teknik pengambilan sampel dilakukan dengan menggunakan purposive random sampling dengan menetapkan kriteria responden dalam penelitian ini (Kerlinger, 2006). Adapun gambaran responden berdasarkan jenis kelamin maupun tingkat pendidikan dapat dilihat pada Tabel 1 berikut:

Tabel 1

Gambaran responden penelitian berdasarkan jenis kelamin dan tingkat pendidikan

\begin{tabular}{ccccccc}
\hline \multirow{2}{*}{ Tingkat Pendidikan } & \multicolumn{6}{c}{ Jenis Kelamin } \\
\cline { 2 - 7 } & \multicolumn{2}{c}{ Laki-laki } & \multicolumn{1}{c}{ Perempuan } & \multicolumn{2}{c}{ Jumlah } \\
\cline { 2 - 7 } & Frek & \% & frek & \% & frek & \% \\
\hline SMA & 2 & 11,8 & 15 & 88,2 & 17 & 100 \\
Akademi & 5 & 42,7 & 7 & 58,3 & 12 & 100 \\
Strata 1 & 11 & 40,8 & 16 & 59,2 & 27 & 100 \\
Strata 2 & 7 & 77,8 & 2 & 22,2 & 9 & 100 \\
Strata 3 & 1 & 33,3 & 2 & 66,7 & 3 & 100 \\
\hline Total Responden & 26 & 43,3 & 42 & 56,7 & 68 & 100 \\
\hline
\end{tabular}

Pada Tabel 1 terlihat bahwa dari total 68 responden yang mengikuti penelitian ini, mayoritas responden $(56,7 \%)$ berjenis kelamin perempuan, sementara dari tingkat pendidikan maka mayoritas responden $(\mathrm{N}=27)$ memiliki latar belakang pendidikan Strata 1. Variabel-variabel dalam penelitian ini adalah komitmen beragama dan pengasuhan holistik yang diukur melalui penilaian responden terhadap komitmen beragama yang dimilikinya, serta penerapan teknik pengasuhan holistik dalam keseharian melakukan pembimbingan terhadap anak-anaknya.

Alat ukur komitmen beragama diadaptasi dari The Religious Commitmen Inventory-10 atau RCI-10 (Worthington dkk., 2003). Dalam menyusun alat ukur ini, peneliti pertama kali menerjemahkan alat ukur ini ke dalam bahasa Indonesia. Kemudian peneliti melakukan back translate kembali ke dalam bahasa Inggris untuk mengetahui apakah terjemahan yang dilakukan oleh peneliti sesuai dengan versi asli bahasa aslinya. Setelah itu peneliti meminta expert judgement kepada dua orang ahli psikometri dan melakukan uji keterbacaan pada dua orang subyek. Setelah uji keterbacaan peneliti melakukan uji coba alat ukur. Kesepuluh butir pernyataan dalam RCI-10 merupakan butir pernyataan yang favorable maupun unfavorable. Dalam penilaian, butir pernyaaan yang bersifat unfavorable akan dibalik terlebih dahulu. Alat ukur ini memiliki enam alternatif jawaban yaitu sangat tidak sesuai, tidak sesuai, agak tidak sesuai, agak sesuai, sesuai, sangat sesuai. Mengacu pada pendapat Worthington 
dkk (2012), maka RCI-10 ini terdiri dari dua dimensi yaitu: (a) intrapersonal religious commitment, yang bermuatan penghayatan individu terhadap keberadaan Tuhan/Allah SWT serta mengagumi ciptaanNya; dan (b) interpersonal religious commitment, yaitu kemampuan individu untuk menghayati keterlibatan dirinya dalam relasinya dengan orang lain, maupun menghayati keterlibatan dirinya dalam relasinya dengan organisasi keagamaan. Contoh pernyataan RCI-10 pada dimensi intrapersonal religious commitment adalah: "agama memiliki arti khusus buat saya karena menjawab banyak pertanyaan dalam kehidupan ini"; sementara contoh pernyataan RCI-10 pada dimensi interpersonal religious commitment adalah "saya senang melakukan kegiatan keagamaan bersama teman-teman yang memiliki keyakinan agama yang sama". Berdasarkan hasil uji coba, maka kesepuluh butir alat ukur pada RCI-10 dapat digunakan, dengan nilai internal konsistensi alpha cronbach sebesar 0,92.

Pengasuhan holistik diukur dengan Skala Pengasuhan Holistik (SPH) (Rahmawati, 2017a) yang telah dimodifikasi untuk versi orang tua. Responden mengisi dengan cara memilih alternatif jawaban dalam enam pilihan, yaitu: sangat tidak sesuai - tidak sesuai - agak tidak sesuai - agar sesuai - sesuai dan sangat sesuai.

Berdasarkan pengujian alat ukur komitmen beragama (The Religious Commitment Inventory) dan alat ukur skala pengasuhan holistik (SPH) berserta dimensi-dimensinya, maka alat ukur ini memiliki reliabilitas yang tergolong pada kategori sedang hingga tinggi (Kaplan \& Saccuzzo, 2004). Secara rinci hasil pengujian internal konsistensi kedua alat ukur tersebut pada Tabel 2 berikut:

Tabel 2

Hasil uji alat ukur Komitmen Beragama dan Skala Pengasuhan Holistik (SPH) versi orang tua

\begin{tabular}{|c|c|c|c|c|c|c|}
\hline No & Alat Ukur & $\begin{array}{c}\text { Jumlah } \\
\text { aitem }\end{array}$ & Rerata & SD & $\begin{array}{c}\text { Kisaran } \\
\text { Nilai }\end{array}$ & $\begin{array}{c}\text { Alpha } \\
\text { Cronbach }\end{array}$ \\
\hline 1 & Intrapersonal-KB & 6 & 13,338 & 1,967 & $8-23$ & 0,760 \\
\hline 2 & Interpersonal-KB & 4 & 12,588 & 1,623 & $7-16$ & 0,675 \\
\hline 3 & Komitmen Beragama (KB) & 10 & 33,222 & 3,644 & $17-40$ & 0,816 \\
\hline 4 & SPH 1_Contoh terpadu & 9 & 40,962 & 5,739 & $21-54$ & 0,804 \\
\hline 5 & SPH 2_Pembiasaan & 8 & 32,729 & 6,035 & $10-48$ & 0,730 \\
\hline 6 & SPH 3_Nasehat efektif & 7 & 29,109 & 5,717 & $14-42$ & 0,776 \\
\hline 7 & $\begin{array}{l}\text { SPH 4_Keseimbangan dalam } \\
\text { perhatian dan pemantuaun }\end{array}$ & 6 & 27,441 & 4,877 & $10-36$ & 0,797 \\
\hline 8 & SPH 5_Konsekuensi proporsional & 5 & 22,890 & 4,568 & $6-30$ & 0,810 \\
\hline 9 & $\begin{array}{l}\text { Skala Pengasuhan Holistik (SPH)- } \\
\text { versi orang tua }\end{array}$ & 35 & 153,122 & 20,758 & $75-207$ & 0,931 \\
\hline
\end{tabular}

Analisis data dalam penelitian dilakukan dengan menggunakan teknik analisis uji perbedaan antar kelompok ( $t$ dan $F$ test), uji korelasi dan uji regresi. Uji $t$ dan $F$ test digunakan untuk menguji perbedaan antara responden berdasarkan jenis kelamin maupun tingkat pendidikan. Uji korelasi digunakan untuk melihat keterkaitan antara variabel penelitian; sementara metode regresi digunakan untuk melihat pengaruh dan besarnya kontribusi antara variabel penelitian. Data diolah secara statistik dengan menggunakan program SPSS versi 20. 


\section{Hasil dan Pembahasan}

Pengujian hipotesis dalam penelitian dilakukan untuk mengetahui korelasi antara komitemen beragama, baik intrapersonal maupun interpersonal, terhadap pengasuhan holistik. Tingkat korelasi antara komitmen beragama dan pengasuhan holistik dijelaskan pada Tabel 3 berikut:

Tabel 3

Hasil korelasi Komitmen Beragama (KB) dengan Pengasuhan Holistik (PH)

\begin{tabular}{|c|c|c|c|c|c|c|c|c|c|}
\hline & $\underset{\mathbf{B}}{\text { Intra_K }}$ & $\underset{\text { B }}{\text { Inter_K }}$ & KB & PH1 & PH2 & PH3 & PH4 & PH5 & $\begin{array}{l}\mathbf{P} \\
\mathbf{H}\end{array}$ \\
\hline$\underset{\text { B }}{\text { Intra_K }}$ & 1 & & & & & & & & \\
\hline$\underset{\mathbf{B}}{\text { Inter_K }}$ & $0,517 * *$ & 1 & & & & & & & \\
\hline KB & 0,760 ** & $0,813^{* *}$ & 1 & & & & & & \\
\hline PH1 & $0,346^{* *}$ & $0,431 * *$ & $\begin{array}{l}0,641 * \\
*\end{array}$ & 1 & & & & & \\
\hline PH2 & $0,347 * *$ & $0,427 * *$ & $\begin{array}{l}0,598 * \\
*\end{array}$ & $0,878^{*}$ & 1 & & & & \\
\hline PH3 & $0,325^{* *}$ & $0,293 *$ & $\begin{array}{l}0,427 * \\
*\end{array}$ & $\begin{array}{l}0,696^{*} \\
*\end{array}$ & $\begin{array}{l}0,770 * \\
*\end{array}$ & 1 & & & \\
\hline PH4 & $0,301 *$ & $0,368^{* *}$ & $\begin{array}{l}0,522 * \\
*\end{array}$ & $\begin{array}{l}0,776^{*} \\
*\end{array}$ & $\begin{array}{l}0,812 * \\
*\end{array}$ & $\begin{array}{l}0,805^{*} \\
*\end{array}$ & 1 & & \\
\hline PH5 & $0,303^{*}$ & $0,362 *$ & $\begin{array}{l}0,514 * \\
*\end{array}$ & $\begin{array}{l}0,734 * \\
*\end{array}$ & $\begin{array}{l}0,713 * \\
*\end{array}$ & $\begin{array}{l}0,736^{*} \\
*\end{array}$ & $\begin{array}{l}0,736^{*} \\
*\end{array}$ & 1 & \\
\hline PH & $0,358^{* *}$ & $0,414 * *$ & $\begin{array}{l}0,596 * \\
*\end{array}$ & $\begin{array}{l}0,905 * \\
*\end{array}$ & $\begin{array}{l}0,913 * \\
*\end{array}$ & $\begin{array}{l}0,890 * \\
*\end{array}$ & $\begin{array}{l}0,924 * \\
*\end{array}$ & $\begin{array}{l}0,877 * \\
*\end{array}$ & 1 \\
\hline
\end{tabular}

** Korelasi signifikan pada tingkat kepercayaan 0,01

* Korelasi signifikan pada tingkat kepercayaan 0,05

Hasil pengujian statistik menunjukkan secara keseluruhan komitmen beragama orang tua memiliki hubungan positif dengan pengasuhan holistik dengan $r=0,596 ; p<$ 0,01 ), dengan sumbangan efektif sebesar $35,5 \%$. Pada dimensi komitmen beragama intrapersonal, diperoleh hasil korelasi sebesar $r=0,358 ; \mathrm{p}<0,01$ yang artinya semakin tinggi tingkat komitmen beragama intrapersonal yang dimiliki orang tua, maka akan semakin besar penerapan pengasuhan holistik. Komitmen beragama intrapersonal memberikan sumbangan pada pengasuhan holistik sebesar 12,8\%. Sementara pada dimensi komitmen beragama interpersonal, diperoleh korelasi sebesar $r=0,414 ; p<$ 0,01 . Hal ini berarti semakin tinggi komitmen beragama interpersonal yang dimiliki orang tua, akan semakin besar penerapan pengasuhan holistik. Komitmen beragama interpersonal memberikan sumbangan pada pengasuhan holistik sebesar 17,1\%.

Korelasi antara dimensi-dimensi komitmen beragama dengan dimensi-dimensi pengasuhan holistik bervariasi. Pada komitmen beragama intrapersonal, korelasi terkuat terjadi dengan dimensi pembiasaan pada pengasuhan holistik dengan sumbangan efektif sebesar 12\%; serta berkorelasi paling rendah dengan dimensi perhatian dan pemantuan. Sedangkan pada komitmen beragama interpersonal, korelasi terkuat terjadi dengan dimensi contoh terpadu dengan sumbangan efektif sebesar $18,6 \%$ dan berkorelasi paling rendah dengan dimensi nasehat efektif pada pengasuhan holistik.

Berdasarkan perhitungan statistik independent sampels t-test pada pengujian perbedaan jenis kelamin, diperoleh nilai Levene's test sebesar $\mathrm{p}>0,05$, baik pada variabel komitmen beragama $(\mathrm{t}(66)=0,86, p=0,932)$ maupun pada variabel pengasuhan 
holistik $(\mathrm{t}(66)=-1,251, \mathrm{p}=0,215)$ antara partisipan laki-laki dan perempuan. Hasil tersebut menunjukkan bahwa tidak terdapat perbedaan komitmen keberagamaan maupun pengasuhn holistik berdasarkan jenis kelamin. Skor yang diperoleh partisipan baik pada variabel komitmen beragama maupun pada variabel pengasuhan holistik tidak dipengaruhi oleh jenis kelamin. Perhitungan uji perbedaan nilai rerata komitmen beragama dan pengasuhan holistik berdasarkan jenis kelamin dapat dilihat pada Tabel 4 .

Tabel 4

Hasil uji perbedaan t tes berdasarkan perbedaan jenis kelamin

\begin{tabular}{ccccc}
\hline & Jenis & Rerata (M) & t & Sign. \\
\hline Kelamin & Laki-laki & 33,27 & 0,86 & 0,932 \\
Pemitmen Beragama & Perempuan & 33,19 & & \\
& Laki-laki & 105,37 & $-1,251$ & 0,215 \\
& Perempuan & 109,76 & & \\
\hline
\end{tabular}

Berdasarkan hasil uji perbandingan antar partisipan berdasarkan tingkat pendidikan dengan menggunakan perhitungan statistik one-way ANOVA ditemukan bahwa tidak terdapat perbedaan yang signifikan antara komitmen beragama $(F(4,63)=$ $1,398, p=0,245)$, maupun pengasuhan holistik $(\mathrm{F}(4,63)=1,392, p=0,247)$, pada tingkat pendidikan SMA, Akademi, S1, S2, maupun S3. Hasil ini menunjukkan bahwa tingkat pendidikan tidak memiliki pengaruh pada komitmen beragama maupun pengasuhan holistik. Hasil uji perbedaan $\mathrm{F}$ tes berdasarkan perbedaan tingkat pendidikan dapat dilihat pada Tabel 5.

Tabel 5

Hasil uji perbedaan $\mathrm{F}$ tes berdasarkan perbedaan tingkat pendidikan

\begin{tabular}{ccccc}
\hline & $\begin{array}{c}\text { Tingkat } \\
\text { Pendidikan }\end{array}$ & Rerata $(\mathbf{M})$ & F & Sign. \\
\hline Komitmen Beragama & SMA & 31,94 & 1,398 & 0,245 \\
& Akademik & 33,33 & & \\
& S1 & 34,33 & & \\
Pengasuhan Holistik & S2 & 32,11 & & \\
& SMA & 33,33 & 1,247 \\
& Akademik & 106,29 & & \\
& S1 & 111,67 & & \\
& S2 & 109,89 & & \\
& S3 & $113,60,44$ & & \\
\hline
\end{tabular}

Secara keseluruhan hasil penelitian ini membuktikan hipotesis yang telah dibangun di awal, bahwa komitmen beragama memberikan kontribusi terhadap pengasuhan holistik. Latar belakang orang tua dengan nilai-nilai agama yang dimiliki, baik pada penghayatan intrapersonal maupun interpersonal, memengaruhi teknik pengasuhan yang dilakukan dalam menunaikan tanggung jawab sebagai orang tua. Teknik pengasuhan holistik yang berlandaskan pada ajaran Islam dipilih oleh orang tua muslim dikarenakan teknik pengasuhan ini dianggap sesuai dengan keyakinan agama yang mereka miliki (Rahmawati, 2016). Orang tua yang memiliki komitmen beragama yang tinggi, berusaha menggunakan prinsip-prinsip agama dalam menjalankan kehidupannya, termasuk di antaranya dalam pengasuhan anak. Pengasuhan holistik yang dilandaskan pada ajaran Islam, menjadi pilihan bagi orang tua yang memiliki 
komitmen beragama, karena metode dan teknik pengasuhan yang terdapat dalam pengasuhan holistik, sejalan dengan keyakinan keberagamaan mereka. Sejumlah peneliti menambahkan, teknik pengasuhan yang dipilih oleh orang tua didasari keinginan untuk mentransmisikan nilai-nilai agama yang mereka miliki agar terwariskan pada anakanaknya (Brownstein, 2008). Pentingnya peran orang tua dalam membentuk nilai-nilai religius yang dimiliki anak, ditunjukkan oleh sejumlah penelitian-penelitian sebelumnya (Dudley \& Wisbey, 2000; Erickson, 1992; Milevsky, Szuchman, \& Milevsky, 2008). Para peneliti tersebut menyimpulkan temuannya, bahwa keyakinan agama yang dimiliki anak berkorelasi signifikan dengan keyakinan agama orang tua mereka.

Dengan komitmen beragama yang dimiliki orang tua, pilihan terhadap teknik pengasuhan tertentu merupakan langkah yang ditempuh untuk memastikan nilai-nilai agama yang dianut tersampaikan secara utuh pada anak-anak mereka. Pada orang tua muslim, menyampaikan nilai-nilai ketauhidan kepada Allah SWT serta kecintaan kepada Rasulullah SAW sebagai panutan dalam kehidupan, dapat dilakukan dengan menggunakan pengasuhan holistik. Pengasuhan holistik yang memiliki teknik qudwah hasanah, al addah, al mau'idzah, al mulahadzah, dan ujarah wa uqobah, mampu mentransmisikan nilai-nilai agama yang dimiliki orang tua kepada anak. Pada teknik qudwah hasanah misalnya, pemberian teladan yang konsisten dalam penanaman tingkah laku positif, mampu mendorong anak-anak untuk mencontoh perilaku positif yang sama dengan apa yang sudah dicontohkan orang tuanya. Sementara pada teknik al 'addah, berupa pembiasaan yang dilakukan orang tua, diharapkan juga mempu membentuk tingkah laku agamis pada anak melalui pemberlakuan kebiasaan sehari-hari, seperti sholat lima waktu, berbuat baik pada orang lain, dan memberikan bantuan/shodaqoh pada yang membutuhkan.

Komitmen beragama interpersonal memiliki pengaruh yang paling besar terhadap teknik pengasuhan contoh terpadu, dibandingkan dengan teknik-teknik lainnya. Penelitian (Brown \& Trevin, 2014), menggarisbawahi pentingnya peran role model dalam pengembangan prinsip-prinsip etika oleh orang tua. Sementara peran komitmen beragama akan mendorong seseorang untuk menjadi contoh terlebih dahulu sebelum menanamkan prinsip etika tertentu pada orang lain (Lane, 2015). Sejalan dengan penelitian tersebut, dalam studi ini ditemukan bila semakin kuat komitmen beragama yang dimiliki orang tua, maka orang tua akan terdorong untuk menggunakan teknik contoh terpadu dalam pengasuhan anak. Apa yang dilakukan oleh orang tua, sejalan dengan ajaran Islam mengenai urgensi menjadi contoh teladan dalam perilaku positif sehari-hari sebelum memerintahkan anak untuk melakukan hal yang sama. Hal ini sesuai dengan pujian Allah SWT kepada Nabi Muhammad SAW sebagai contoh teladan yang baik/qudwah hasanah.

Sementara penelaahan terhadap dimensi komitmen beragama intrapersonal terhadap teknik pengasuhan holistik menunjukkan bahwa dimensi komitmen beragama intrapersonal memiliki pengaruh yang paling besar terhadap teknik pembiasaan, dibandingkan dengan teknik-teknik pengasuhan lainnya. Pembiasaan sendiri menjadi teknik pengasuhan yang efektif dalam mengatasi problemetika anak dan kerap dipilih orang tua untuk membentuk perilaku anak (Bilsky, 2016). Hal ini berarti orang tua yang memiliki komitmen beragama intrapersonal, yang ditandai oleh penghayatan individu terhadap hubungannya dengan Allah SWT, cenderung akan lebih kuat memilih teknik pembiasaan dalam pengasuhan anak-anaknya, dibandingkan teknik pengasuhan lainnya. Orangtua yang memiliki komitmen keberagamaan intrapersonal yang tinggi mampu menghayati hubungannya dengan Allah SWT dan menjaga kebiasaan ibadah-ibadah 
kepada Allah. Kebiasaan pada orangtua ini akan ditransfer kepada anak-anaknya dengan pembiasaan-pembiasaan postif dalam pengasuhan sehari-hari. Kecenderungan ini sejalan dengan anjuran Rasulullah SAW pada hadits berikut: "Ajarkanlah anak-anak dan keluarga kalian kebaikan, dan didiklah mereka" (HR Abdurrazaq dan Said bin Manshur dalam Ulwan, 2014).

Hasil penelitian menunjukkan bahwa tidak terdapat perbedaan antara orang tua berjenis kelamin laki-laki dan perempuan pada komitmen beragama maupun pengasuhan holistik. Pada komitmen beragama, hasil yang diperoleh dalam penelitian ini sejalan dengan penelitian Rachmanto (2011) pada partisipan usia dewasa muda yang menemukan bahwa tidak ada perbedaan komitmen beragama berdasarkan jenis kelamin.

Penelitian sebelumnya mengenai pengaruh jenis kelamin terhadap penanaman nilai keagamaan menunjukkan hasil yang bervariasi. Heaven, Ciarrochi, \& Leeson (2010) mengekplorasi peran ayah dan ibu dalam mentransmisikan nilai-nilai agama dan menemukan hasil bahwa ibu umumnya memiliki peran lebih kuat dibandingkan ayah dalam menanamkan nilai-nilai keagamaan pada proses pengasuhan. Sementara penelitian Lane (2015) menunjukkan hasil bahwa peran ayah lebih kuat dalam penanaman nilai-nilai agama. Pada pengasuhan holistik, baik peran ayah dan ibu dalam penerapan teknik pengasuhan tidak ditemukan perbedaan. Hasil dalam penelitian ini menunjukkan tidak ada pengaruh jenis kelamin orangtua dalam penerapan pengasuhan holistik. Hal ini disebabkan karena teknik-teknik pengasuhan holistik digunakan secara universal pada proses pembimbingan anak, baik oleh ayah maupun ibu sebagai pendidik, yang pada akhirnya akan menjaga konsistensi pengasuhan yang diberikan untuk anak (Ulwan, 2014).

Hasil penelitian menunjukkan bahwa komitmen beragama memiliki kontribusi signifikan pada pengasuhan holistik. Hasil ini sejalan dengan penelitian-penelitian sebelumnya yang menyatakan bahwa latar belakang orang tua akan memengaruhi pola pengasuhan yang diterapkan dalam pembimbinan anak (Abar, Carter, \& Winsler, 2009; Lane, 2015; Sol, 2001). Komitmen beragama orang tua melandasi nilai-nilai yang dimiliki orang tua dalam memilih teknik-teknik penasuhan yang tepat, yang diyakini dalam mengarahkan anak untuk mencapai harapan keluarga. Pemilihan orang tua yang memiliki komitmen beragama pada pengasuhan holistik, sesuai dengan anjuran yang terdapat di dalam Al Qur'an, tentang perintah kepada orang tua untuk menjaga diri mereka maupun keluarga mereka dari siksa api neraka (Qur'an 66: 6). Bagi orang tua dengan kesadaran agama yang kuat, menjaga keluarga menjadi salah satu kewajiban yang diprioritaskan. Hal ini juga sesuai dengan anjuran yang disampaikan oleh Rasulullah SAW pada hadits berikut ini:

"Seorang ayah adalah penanggung jawab pada keluarganya dan akan dimintai pertanggungjawaban terhadap apa yang dipimpinnya. Seorang ibu bertanggung jawab pada suami dan anak-anaknya, dan akan diminta pertanggungjawaban mengenai apa yang diamanahkan padanya" (Hadits Riwayat Bukhari \& Muslim dalam Ulwan, 2014).

Ketika orang tua memiliki komitmen beragama yang tinggi, yang tercermin dalam kebersetujuan yang positif terhadap ajaran agama ataupun pengambilan keputusan sehari-hari atas dasar agama, maka orang tua akan memilih pola pengasuhan yang sesuai nilai yang mereka anut. Pengasuhan holistik menjadi jawaban bagi orang tua muslim yang memiliki komitmen beragama tinggi, karena teknik-teknik pengasuhan dalam metode ini sesuai dengan identifikasi diri mereka terhadap makna keberagamaan. Komitmen beragama yang tinggi juga akan mengarahkan orang tua untuk berinteraksi intens dengan kitab sucinya. Bagi orang tua muslim, terdapat ayat-ayat yang jelas di 
dalam Al Qur'an maupun sumber lainnya seperti Al Hadits, yang mengarahkan orang tua untuk membimbing anak-anaknya dengan teknik pengasuhan Islami.

Dalam penelitian ini terdapat beberapa kelemahan, seperti jumlah sampel yang terbatas, latar belakang sampel penelitian dari kalangan urban yang memiliki karakteristik tersendiri; orang tua pada sampel penelitian ini memiliki anak yang berada pada usia SD, serta metode yang digunakan masih terbatas pada metode kuantitaf. Ada baiknya untuk penelitian selanjutnya, sampel dapat diperluas baik dari sisi kuantitas subyek penelitian maupun ragam latar belakang, sehingga penjelasan terhadap variabel penelitian dapat lebih kaya. Penggunaan metode lain, seperti menyertainya dengan metode kualitatif di samping metode kuantitatif, diprediksi juga akan lebih memperkaya data hasil penelitian. Misalnya dalam mengeksplorasi pengasuhan holistik yang sejalan dengan keyakinan ajaran Islam pada area fungsi perkembangan anak. Penelitian selanjutnya juga disarankan untuk mengujicobakan kontribusi komitmen beragama serta pengasuhan holistik pada orang tua dengan anak-anak yang sudah beranjak remaja. Eksplorasi ini diharapkan dapat memperkaya pengembangan penelitian psikologi, khususnya yang berakitan dengan komitmen beragama dan pengasuhan holistik.

\section{Simpulan}

Pengasuhan holistik merupakan konsep pengasuhan Islami bersandarkan pada nilai-nilai yang terdapat dalam Al Qur'an dan Hadits yang diharapkan mampu menjawab persoalan pengasuhan anak oleh keluarga-keluarga muslim. Aplikasi teknikteknik pengasuhan holistik oleh para orang tua tidak terlepas dari komitmen beragama yang dimiliki oleh orang tua. Komitmen beragama orang tua mengarahkan pilihan orang tua untuk menggunakan teknik pengasuhan holistik, sebagai bentuk pengasuhan yang dapat mentransmisikan nilai-nilai agama yang dimiliki orang tua kepada anakanak mereka. Baik pada dimensi komitmen beragama intrapersonal yang dicirikan oleh penghayatan inidividu dalam hubungannya dengan Allah SWT Sang Pencipta; maupun pada dimensi komitmen beragama intrapersonal yang dicirikan oleh kemampuan individu untuk menghayati keterlibatan dirinya dalam relasinya dengan orang lain maupun dalam relasinya dengan organisasi keagamaan, menunjukkan kontribusi yang positif terhadap penerapan teknik-teknik pengasuhan holistik. Fenomena meningkatnya kesadaran beragama di kalangan orang tua perlu diiringi oleh pemberian alternatif pengasuhan yang sesuai dengan nilai-nilai agama yang dimiliki orang tua sehingga selaras dengan keyakinannya. Atas dasar pertimbangan tersebut, maka terobosan untuk memperkenalkan teknik pengasuhan holistik memiliki urgensi penting dalam pengembangan konsep-konsep Islam yang dibutuhkan para orang tua dalam pengaplikasian keyakinan agama mereka dalam praktik keseharian berperilaku.

\section{Daftar Pustaka}

Abar, B., Carter, K. L., \& Winsler, A. (2009). The effects of maternal parenting style and religious commitment on self-regulation, academic achievement, and risk behavior among African-American parochial college students. Journal of Adolescence, $32(2)$, 259-273. https://doi.org/http://dx.doi.org/10.1016/j.adolescence.2008.03.008 
Adhim, M. . (2015). Positive parenting. Jogjakarta: Pro-U Media.

Bilsky, S. (2016). The Role of Child Anxiety in Parent Sick Role Reinforcement. Retrieved from https://search.proquest.com/docview/1789629148?accountid=62688

Brown, M. E., \& Trevin, L. K. (2014). Do Role Models Matter? An Investigation of Role Modeling as an Antecedent of Perceived Ethical Leadership, 587-598. https://doi.org/10.1007/s10551-013-1769-0

Brownstein, D. (2008). Parenting styles, religious personality, and the religious development of Orthodox Jewish adolescents. Scranton: Marywood University.

Dudley, R. L., \& Wisbey, R. L. (2000). The relationship of parenting styles to commitment to the church among young adults. Religious Education, 95.

Erickson, J. A. (1992). Adolescent religious development and commitment: A structural equation model of the role of family, peer group, and educational influences. Journal for the Scientific Study of Religion, 31, 131-152.

Gammon, C. (2016). Mediators and moderators of the relationship between family variables and child physical activity. Retrieved from https://search.proquest.com/docview/1823285600?accountid=62688

Hafizh, M. N. . (2012). Prophetic perenting. Jogjakarta: Pro-U Media.

Heaven, P. C. L., Ciarrochi, J., \& Leeson, P. (2010). Parental styles and religious values among teenagers: A 3-year prospective analysis (171(1)). Scranton: Marywood University.

Hughoghi, M \& Long, N. (2004). Handbook of Parenting. Theory and Reserach for Practice. London: Sage Publication. London: Sage Publication.

Jones, M. Y. (2012). Health and religious commitment among college students: The effects of health behavior, mental health, and social support. Retrieved from https://search.proquest.com/docview/1270777761 ?accountid=17242

Kaplan, R. M. \& Saccuzzo, D. P. (2004). Psychological testing; principles, applications, and issues. Scitech Book News; Portland (3rd ed.). Ringgold Inc. Retrieved from https://search.proquest.com/docview/200085398?accountid=62688

Kerlinger, F. N. (2006). Asas-asas Penelitian Behavioral. Jogjakarta: Gadjah Mada University Press.

Lane, T. (2015). Impact of parents' religious background on parenting style and children's religiosity in the orthodox jewish community. Retrieved from https://search.proquest.com/docview/1716383160?accountid=17242

Milevsky, I. M., Szuchman, L., \& Milevsky, A. (2008). Transmission of religious beliefs in college students. Mental Health, Religion \& Culture, 11(4), 423-434.

Mounts, N. S. (2002). Parental Management of Adolescent Peer Relationships in Context: The Role of Parenting Style, 16(1), 58-69. https://doi.org/10.1037//0893-3200.16.1.58

Rachmanto, S. F. (2011). Hubungan antara Trait Kepribadian dengan Komitmen 
Beragama pada Kelompok Dewasa Muda dan Dewasa Madya di Jakarta. Depok: Universitas Indonesia.

Rahmawati, S. W. (2016). Holistic Parenting: Contribution Islamic Parenting in preventing school bullying in Jakarta, Indonesia. Journal of Education and Social Science, 5(2), 82-85. Retrieved from http://jesoc.com/wpcontent/uploads/2016/12/KC5_37.pdf

Rahmawati, S. W. (2017a). Bullying siswa di sekolah menengah atas: Peran holistic parenting dan iklim sekolah terhadap bullying melalui variabel mediasi trait kepribadian lima besar. Bandung: Universitas Padjadjaran.

Rahmawati, S. W. (2017b). Peran Pengasuhan Holistik Terhadap Altruisme dan Bullying. Humanitas Journal, 14(1), 10-25. https://doi.org/http://dx.doi.org/10.26555/humanitas.v14i1.4316

Sol, H. (2001). An investigation of the relationship between parent religious commitment, adolescent religious commitment, and parent-adolescent communication in the context of Korean immigrant families. https://doi.org/https://search.proquest.com/docview/304708016?accountid=1724 2

Spraitz, J. D. (2011). Parenting styles and criminal involvement : a test of Baumrind' $s$ typology. Indiana University of Pennsylvania.

Ulwan A.N. (2014). Pendidikan Anak dalam Islam (Rahman, A.H., Terj.). Solo: Insan Kamil.

Worthington, E. L., Wade, N. G., Hight, T. L., Ripley, J. S., Mccullough, M. E., Berry, J. W., ... Connor, L. O. (2003). The Religious Commitment Inventory - 10 : Development, Refinement , and Validation of a Brief Scale for Research and Counseling, 50(1), 84-96. https://doi.org/10.1037/0022-0167.50.1.84 